\title{
Biorefinery Approach from Nannochloropsis oceanica CCALA 978: Neutral Lipid and Carotenoid Co-Production Under Nitrate or Phosphate Deprivation
}

\author{
Natalia Bongiovani ${ }^{1} \cdot$ Cecilia A. Popovich ${ }^{1,2}$ D $\cdot$ Ana María Martínez ${ }^{3}$ - Diana Constenla ${ }^{4} \cdot$ Patricia I. Leonardi $^{1}$
}

(C) Springer Science+Business Media, LLC, part of Springer Nature 2019

\begin{abstract}
The large-scale culture of microalgae has become a focus of interest for the biorefinery industry, combining the production of biofuels with that of other value-added bioproducts and thus increasing the profitability of the process. In order to evaluate its potential as biodiesel feedstock under a biorefinery approach, the biomass, pigment, nutrient, total lipid and lipid fraction kinetics of the Argentinian Nannochloropsis oceanica CCALA 978 strain were analysed. The species was first cultivated under optimal conditions ( $\mathrm{f} / 2$ medium) and then transferred to nutritional stress conditions (N-deprivation or P-deprivation media). Under complete f/2 medium, $N$. oceanica presented maximum growth rate $(\mu)$ and chlorophyll- $a$ values and minimum values for lipid and carotenoid content. The high nutrient consumption rate $(\mathrm{N}$ or $\mathrm{P})$ in this exponential phase was associated with increasing cell density. Under both nitrate and phosphate deprivation, $\mu$ was drastically reduced but biomass production reached its highest values, indicating a phase of metabolite accumulation. Maximum values of total lipids (ca. 39\% dw) and carotenoids (1100 $\times$ $10^{-3} \pm 15 \mu \mathrm{g} \mathrm{mL}^{-1}$ ) were obtained under nitrate deprivation. In addition, total lipid composition was characterized by $92 \%$ neutral lipids, $0.7 \%$ phospholipids, a high percentage of C16:1 (ca. $37 \%$ of total fatty acids) and minimum values of PUFA (5.9\% of total fatty acids). Biodiesel properties inferred from the fatty acid methyl ester profile of neutral lipids meet the standards established by EN 14214 and ASTMD 6751-08. Although N and P deficiency both produced an increase in neutral lipids in the studied strain, under a biorefinery approach, nitrate deprivation is considered to be a better method of stress induction than phosphate deprivation for the purpose of co-producing neutral lipids for biodiesel and value-added pigments.
\end{abstract}

Keywords Marine microalga biomass $\cdot$ Nutrient kinetics $\cdot$ Lipid fractions $\cdot$ Pigments $\cdot$ Biodiesel feedstock

Cecilia A. Popovich

bmpopovi@criba.edu.ar

1 Departamento de Biología, Bioquímica y Farmacia, Centro de Recursos Naturales Renovables de la Zona Semiárida (CERZOS) CONICET-UNS, Universidad Nacional del Sur (UNS), Camino La Carrindanga, km 7, San Juan 670, Bahía Blanca, Argentina

2 Centro de Emprendedorismo y Desarrollo Territorial Sostenible (CEDETS) CIC-UPSO, Ciudad de Cali 320, Bahía Blanca, Argentina

3 Laboratorio de Química Ambiental, Departamento de Química, INQUISUR (CONICET-UNS), Universidad Nacional del Sur, Av. Alem 1253, 8000 Bahía Blanca, Argentina

4 Departamento de Ingeniería Química Universidad Nacional del Sur, Planta Piloto de Ingeniería Química (PLAPIQUI) UNS-CONICET, Camino La Carrindanga km 7, 8000 Bahía Blanca, Argentina

\section{Introduction}

Biodiesel derived from microalgae is considered a promising alternative source of energy in the framework of emergent technologies [1]. Specifically, oleaginous microalgae can produce high amounts of neutral lipids (NL), the main feedstock for biodiesel transesterification [2]. Even though the production of biodiesel and its blends is technically feasible [3, 4], the culture of microalgae on a large scale is still not economically profitable. Strategies used to lower costs and increase yields include the use of flue gases, the utilization of wastewater for the nutrient supply and the production of valuable co-products [5]. In particular, some species of microalgae are able to synthetize polyunsaturated fatty acids, natural dyes, carotenoids, enzyme polymers, peptides, toxins and sterols with profitable applications in different industrial sectors [6].

Microalgae biorefineries are of interest since they combine the production of biofuels and other value-added products, increasing the viability of the process [7]. However, highly 
diverse biorefinery scenarios arising from various factors affect microalgal culture (for example, microalgal strain, cell size, optimal environmental factors, stress factors, culture units). A viable strategy requires the selection of a species with the capacity to produce, within the same environmental scenario, suitable neutral lipids for biodiesel and valuable metabolites [8]. Obtaining biomass that contains all the products to be extracted in the same culture phase offers a significant advantage since harvesting can represent up to 20 to $30 \%$ of the culture costs [9].

Nannochloropsis is a microalgal genus belonging to the Eustigmatophyceae class whose species are characterized by their robustness and plasticity. Most are marine species and can grow under different environmental conditions [10-15]. As with other microalgae species, the biochemical composition of Nannochloropsis varies according to environmental factors and culture strategies [1]. Several studies worldwide have shown the promising potential of this species as a candidate for biodiesel production due to its ability to accumulate large amounts of neutral lipids, mainly triglycerides (TAG) [16-18]. Furthermore, Nannochloropsis species produce valuable products, such as carotenoids, eicosapentaenoic acid (EPA) and proteins [7, 19]. The potential of Nannochloropsis cultures has been studied under two scenarios: (1) biodiesel production and EPA as a nutraceutical biocompound [20,21] and (2) biodiesel production and carotenoids for food [7, 14]. Contrary to TAG production, the synthesis of PUFA is more active in cells growing under the exponential phase. Respect to second scenario, the synthesis of carotenoids in some Nannochloropsis strains has been reported together with lipid accumulation when cells are exposed to nutrient limitation [7]. Carotenoids can be used in food, feed, cosmetics, biomaterials, nanostructures and the pharmaceutical industry; however, most of the recent attention has been focused on their function as antioxidants. The global carotenoid market was estimated to be worth $\sim 1.24$ billion USD in 2016, projected to increase to $\sim 1.53$ billion USD by 2021 , at a compound annual growth rate (CAGR) of $3.78 \%$ from 2016 to 2021 [22]. This latter scenario therefore adds to the strategic interest in enhancing knowledge of biorefineries based on Nannochloropsis species.

In particular, with regard Nannochloropsis oceanica, Dong et al. [23] reported on the synthesis of total lipids and accessory pigments in $N$. oceanica IMET1 under long-term nitrogen starvation, while Solovchenko et al. [14] evaluated the fatty acid and carotenoid profiles in $N$. oceanica CCALA 804 under nitrogen deficiency. Thus, the effect of $\mathrm{N}$ or $\mathrm{P}$ deprivation on the simultaneous production of neutral lipids for biodiesel and carotenoids as a value-added co-product in the Argentinian N. oceanica CCALA 978 strain was systematically evaluated. For this, the strain was cultivated under optimal and nutritional stress conditions ( $\mathrm{N}$-free or P-free media) in order to obtain basic information on the following aspects: (1) biomass and pigment production, (2) nutrient kinetics, (3) total lipids, neutral lipids and polar lipids, (4) fatty acid methyl ester (FAME) profiles and (5) oil quality for biodiesel production. The results of this study are expected to provide valuable input for large-scale cultures of $N$. oceanica under a biorefinery approach.

\section{Materials and Methods}

\section{Algal Strain and Culture Conditions}

Nannochloropsis oceanica CCALA 978 (Culture Collection of Autotrophic Organisms, Institute of Botany, Academy of Sciences of the Czech Republic) was isolated from the Southwestern Atlantic Ocean coast $\left(65^{\circ} 01^{\prime} \mathrm{W}, 43^{\circ} 18^{\prime} \mathrm{S}\right.$, Argentina) and provided by CRIAR, Instituto de Biología Marina y Pesquera Almirante Storni, San Antonio Oeste, Río Negro province, Argentina. The molecular and phylogenetic identification of the species was carried out by Bongiovani et al. [24]. The culture medium was prepared with natural seawater from Bahía Blanca Estuary (Argentina) and adjusted to a salinity value of 30 . The seawater was filtered by cellulose acetate membrane $(0.45-\mu \mathrm{m}$ size $)$, sterilized and enriched with $\mathrm{f} / 2$ nutrients according to Guillard [25] as follows: $\mathrm{NaNO}_{3}(880 \mu \mathrm{M}), \mathrm{NaH}_{2} \mathrm{PO}_{4}(36 \mu \mathrm{M})$, trace metal $\left(\mathrm{CuSO}_{4} \cdot 5 \mathrm{H}_{2} \mathrm{O}(0.039 \mu \mathrm{M}), \mathrm{ZnSO}_{4} \cdot 7 \mathrm{H}_{2} \mathrm{O}(0.076 \mu \mathrm{M})\right.$, $\mathrm{CoCl}_{2} \cdot 6 \mathrm{H}_{2} \mathrm{O}(0.042 \mu \mathrm{M}), \mathrm{MnCl}_{2} \cdot 4 \mathrm{H}_{2} \mathrm{O}(0.91 \mu \mathrm{M})$, $\left.\mathrm{Na}_{2} \mathrm{MoO}_{4} \cdot 2 \mathrm{H}_{2} \mathrm{O}(0.026 \mu \mathrm{M})\right)$, TRIS $\left(1.65 \times 10^{6} \mu \mathrm{M}\right)$, vita$\min \mathrm{B} 12\left(3.69 \times 10^{-4} \mu \mathrm{M}\right)$, biotin $\left(2.05 \times 10^{-3} \mu \mathrm{M}\right)$ and vita$\min \mathrm{B} 1(0.29 \mu \mathrm{M})$.

Nannochloropsis oceanica cells were cultured in 2-L Erlenmeyer flasks at $25 \pm 1{ }^{\circ} \mathrm{C}$ with continuous bubbling of air (500-700 $\mathrm{cm}^{3} \mathrm{~min}^{-1}$ ) enriched with $\mathrm{CO}_{2}$ (1\%) during 4$5 \mathrm{~h}$ every day. Light was supplied by cool white Philips fluorescent tubes in a 16:8-h light-dark photoperiod at an average of $100 \mu \mathrm{mol}$ photons $\mathrm{m}^{-2} \mathrm{~s}^{-1}$, measured by a photoradiometer (LICOR, LI-192SB $2 \pi$ Model).

\section{Cultures with Complete f/2 Medium (Culture Step 1)}

Cultures were grown in triplicate in $2 \mathrm{~L}$ of complete $\mathrm{f} / 2$ medium in batch mode (culture step 1). The cultures were harvested in the exponential phase by centrifugation $(3500 \mathrm{~g})$ on day 7. A pellet from one culture was washed three times with distilled water (3 volumes of distilled water) and kept at $20{ }^{\circ} \mathrm{C}$ until lipid analysis.

\section{Cultures with Nitrate or Phosphate Deprivation (Culture Step} 2)

The second pellet from cells in the exponential phase of step 1 was resuspended in $\mathrm{f} / 2$ medium under nitrate deprivation $[\mathrm{f} / 2$ 
$(\mathrm{N}-)]$ in order to evaluate the effect of the absence of nitrogen. The third pellet from step 1 was resuspended in $\mathrm{f} / 2$ medium under phosphate deprivation $[\mathrm{f} / 2(\mathrm{P}-)]$ in order to evaluate the effect of the absence of phosphorous. Finally, the cultures were centrifuged on day 21 and the biomass was washed three times with distilled water ( 3 volumes of distilled water) and kept at $-20{ }^{\circ} \mathrm{C}$ until lipid analysis.

\section{Determinations of Growth, Dry Cell Weight and Biomass Productivity}

The cell density (no. cell $\mathrm{mL}^{-1}$ ) was determined daily by counting three replicate samples in a Neubauer haemocytometer under an optical microscope Leica DM 2000 . The specific growth rate $(\mu)$ was estimated during the period of exponential growth by a least squares fit to a straight line of logarithmically transformed data [25]. The dry weight (DW) was estimated by a modified gravimetric method according to Chini Zittelli et al. [26]. Samples of $5 \mathrm{~mL}$ were filtered through pre-conditioned and pre-weighed filters (Munktell GF/F). The filters with samples were then washed three times with $20 \mathrm{~mL}$ distilled water and dried overnight at $60{ }^{\circ} \mathrm{C}$ until constant weight. Biomass productivity $\left(\mathrm{mg} \mathrm{mL}^{-1}\right.$ day $\left.^{-1}\right)$ was calculated as the difference between initial and final dry weight biomasses divided by the duration of the cultivation period. Culture samples were taken in triplicate every 2 or 3 days.

\section{Chlorophyll- $a$ and Total Carotenoid Measurements}

For the chlorophyll- $a(\mathrm{Chl} a$ ) and total carotenoid (Car) content determinations, 4-mL samples were taken every 2 or 3 days and filtered through GF/F filters (Munktell MGF). The filters were treated with $5 \mathrm{~mL}$ absolute methanol three times and kept overnight in the dark at $-18{ }^{\circ} \mathrm{C}$ [27]. The extract was clarified by filtration and the Chl $a$ and Car contents were determined spectrophotometrically with a spectrophotometer Shimatzu UV-Visible 1603 at 665 and $480 \mathrm{~nm}$, respectively. The $\mathrm{Chl} a$ and Car contents were estimated according to the following equation: $\mathrm{Chl} a\left(\mu \mathrm{L} \mathrm{mL}{ }^{-1}\right)=13.9$ $\left(A_{665}-A_{750}\right)$ [28] and $\operatorname{Car}\left(\mu \mathrm{L} \mathrm{mL}{ }^{-1}\right)=4\left(A_{480}-A_{750}\right)$ [29]. The absorption spectra of $N$. oceanica CCALA 978 were recorded and normalized to cell density. Determinations were carried out in triplicate.

\section{Nutrient Analysis}

For the determination of dissolved nitrate and phosphate concentrations, 4-mL samples were taken every 2 or 3 days and filtered through $0.7-\mu \mathrm{m}$-pore $\mathrm{GF} / \mathrm{F}$ filters. The cell-free supernatant was kept at $-20{ }^{\circ} \mathrm{C}$ until nutrient analysis. Phosphate concentration was determined using the orthophosphate method according to Murphy and Riley [30]. Nitrate concentration was determined using the $\mathrm{Cd} / \mathrm{Cu}$ column reduction method according to Strickland and Parsons [31]. The absorbance signals of nitrate and phosphate were read at $543 \mathrm{~nm}$ and $885 \mathrm{~nm}$, respectively. Absorbance was measured using a spectrophotometer SHIMATZU UV-VIS model UV-1603.

\section{Lipid Analysis}

\section{Neutral Lipid Kinetics}

For neutral lipid kinetics, 5-mL samples in triplicate were taken every 2 or 3 days and frozen at $-20{ }^{\circ} \mathrm{C}$ until analysis. The determination of neutral lipids was done by the spectrofluorometric method with Nile Red [27]. The fluorescence intensity (FI) was measured using a spectrofluorometer RF5301PC Schimadzu at excitation/emission wavelengths of $480 / 570 \mathrm{~nm}$, respectively. The relative fluorescence intensity (RFI) was calculated as the subtraction of both the fluorescence of microalgal cell suspensions and the selffluorescence of Nile Red. Samples were taken in triplicate.

\section{Total Lipid Extraction}

Total lipid (TL) extraction was performed according to a modified Folch method [32] assisted with ultrasound [33]. Freezedried samples in quadruplicate of 150-200 $\mathrm{mg}$ of biomass were treated with $4 \mathrm{~mL}$ of chloroform:methanol $(2: 1 \mathrm{v} / \mathrm{v})$, vortexed thoroughly for 1-2 min and ultrasonicated during $15 \mathrm{~min}$ at room temperature. The mixture was then centrifuged at $3600 \mathrm{~g}$ for $5 \mathrm{~min}$ and the supernatant was recovered and collected in a funnel separator; this procedure was repeated three times. The supernatant was washed twice with $20 \%$ $\mathrm{NaCl} 0.9 \%(\mathrm{w} / \mathrm{w}$ ) and allowed to stand until a biphasic system was achieved. The lower phase containing the extracted lipids was recovered into a glass flask, evaporated to dryness under a nitrogen stream and kept at $-20{ }^{\circ} \mathrm{C}$ until lipid fractionation.

\section{Lipid Fractionation}

Total lipids were fractionated into neutral lipids (NL), glycolipids (GL) and phospholipids (PL) using a silica Sep-Pack cartridge of $1000 \mathrm{mg}$ (J. T. Baker Inc., Phillipsburg, N. J.) according to the protocol described by Berge et al. [34]. The procedure consisted of the following steps: (i) conditioning of the silica cartridge eluting $30 \mathrm{~mL}$ of chloroform, (ii) sample loading (25-30 mg of total lipid extract diluted in $5 \mathrm{~mL}$ of chloroform); (iii) recovery of NL from the adsorbent bed by elution with $15 \mathrm{~mL}$ of a solution of chloroform:acetic acid (9:1 $\mathrm{v} / \mathrm{v}$ ); (iv) GL recovery by elution with $20 \mathrm{~mL}$ of a solution of acetone:methanol $(9: 1 \mathrm{v} / \mathrm{v})$ and finally (v) PL recovery by elution with $20 \mathrm{~mL}$ of methanol. Each fraction was collected into a pre-weighed conical glass vial, evaporated until dryness 
under a clean nitrogen stream and weighed. Two replicates of each lipid fraction were made.

\section{Methyl Ester Derivation and Fatty Acid Analysis}

The fatty acid derivation was carried out according to a modified method of Morrison and Smith [35]. An aliquot of total lipid and each lipid fraction (about 25-30 mg) was weighed in a conical thermo-resistant flask. Two millilitres of $\mathrm{KOH}-$ methanol solution $(10 \% \mathrm{w} / \mathrm{v})$ was added and shaken vigorously in a vortex. The air was purged under nitrogen stream and the flask was hermetically sealed. The flask with lipid$\mathrm{KOH}$ :methanol solution was heated for $45 \mathrm{~min}$ in a water bath at $80^{\circ} \mathrm{C}$. The unsaponifiable material was then extracted using $2 \mathrm{~mL}$ of petroleum ether, twice. The upper phase was discarded. Concentrated $\mathrm{HCl}$ was added to the lower phase and shaken in a vortex tube during $1 \mathrm{~min}$. Petroleum ether $(2 \mathrm{~mL})$ was aggregated and shaken vigorously in a vortex, recovering the FA in the upper phase. This step was repeated twice. The ether-lipid extract was dried under a nitrogen stream. A solution of $\mathrm{BF}_{3}-$ methanol $(10 \% \mathrm{v} / \mathrm{v}$, Sigma Aldrich) was added and the samples were incubated at $80^{\circ} \mathrm{C}$ for $30 \mathrm{~min}$ in a water bath. Then, fatty acid methyl esters (FAME) were extracted twice with petroleum ether $(2 \mathrm{~mL})$, the upper phase was recovered and the esters were evaporated to dryness under a nitrogen stream. Finally, hexane (chromatography grade) was added to a final volume of $1 \mathrm{~mL}$ for total and neutral lipids and $0.5 \mathrm{~mL}$ for glycolipids and phospholipids. FAME were analysed by gas chromatography with a gas chromatograph HP Agilent 4890D, equipped with a flame-ionization detector at a temperature of $260{ }^{\circ} \mathrm{C}$, a split/ splitless injector and a capillary column SP-2560 (100 m, $0.25 \mathrm{~mm}$ and $0.2 \mu \mathrm{m}$ ) (Supelco Inc., Bellefonte, PA). The carrier gas was high purity hydrogen at $18 \mathrm{~cm} \mathrm{~s}^{-1}$. The GC oven was initially held at $140{ }^{\circ} \mathrm{C}$ for $5 \mathrm{~min}$ after which the temperature was increased at $4{ }^{\circ} \mathrm{C} / \mathrm{min}$ to $240{ }^{\circ} \mathrm{C}$ and held isothermal for $15 \mathrm{~min}$. The detection limit of the chromatographic method was set at $0.01 \%$. The HP 3398A GC Chemstation Software (Hewlett Packard, 1998) was used for chromatographic analysis. FAME identification was performed by comparison with standard certificate material, Supelco FAME 10 mix 37 (Bellefonte, PA, USA), according to the AOCS Official Method Ce 1b-89. Four replicates of TL and each lipid fraction were made. All employed solvents were of analytical grade.

\section{Biodiesel Quality from Fatty Acid Profiles}

Different biodiesel properties were estimated on the basis of the fatty acid profiles of total and neutral lipids. Average degree of unsaturation (ADU), iodine value (IV), cetane number $(\mathrm{CN})$, cloud point $(\mathrm{CP})$, specific gravity $(\mathrm{SG})$, kinematic viscosity (KV) and higher heating value (HHV) were calculated according to Hoekman et al. [36]; cold filter plugging points were estimated according to Talebi et al. [37]. The algorithms were as follows:

$$
\begin{aligned}
& A D U=\sum M Y_{i} \\
& I V=74.373 A D U+12.71 \\
& C N=-6.6684 A D U+62.876 \\
& C P=-13.356 A D U+19.994 \\
& S G=0.0055 A D U+0.8726 \\
& K V=-0.6316 A D U+5.2065 \\
& H H V=1.7601 A D U+38.534 \\
& C F P P=(3.14171417 \times L C S F)-16.477
\end{aligned}
$$

where $Y_{\mathrm{i}}$ is the percentage fraction of each fatty acid (FA) component, $M$ is the number of carbon-carbon double bonds in each FA component and LCSF is the long-chain saturated factor.

\section{Statistical Analysis}

The differences in mean values of total lipid and lipid fractions and between mean value percentages of fatty acids were assessed by two-way ANOVA, followed by Fisher's test in order to identify the sources of detected significance. In all cases, comparisons that showed $p<0.05$ were considered significant. All statistical analyses were carried out with Infostat Software [38].

\section{Results and Discussion}

\section{Growth, Biomass Production, Nutrient and Pigment Kinetics of $N$. oceanica CCALA 978}

The growth rate, biomass production and productivity and nutrient kinetics of $N$. oceanica growing first in a complete medium (f/2) (culture step 1) and then under nutrient deprivation [f/2 (N-) or f/2 (P-)] (culture step 2) are shown in Fig. 1. Under complete f/2 medium, $N$. oceanica CCALA 978 presented an exponential growth phase until day 7 with a $\mu$ of $0.46 \pm 0.02$ day $^{-1}$ and a maximum cell density of ca. $35 \times$ $10^{6}$ cells $\mathrm{mL}^{-1}$ (Fig. 1a). Maximum biomass production and productivity were ca. $320 \mathrm{mg} \mathrm{L}^{-1}$ (day 7) and $37.8 \mathrm{mg} \mathrm{L}^{-1}$ day $^{-1}$, respectively (Fig. 1b, c). Under nutrient deprivation, $\mu$ was drastically reduced to 0.02 day $^{-1}$ and 0.003 day $^{-1}$ for $\mathrm{f} / 2(\mathrm{~N}-)$ and $\mathrm{f} / 2(\mathrm{P}-)$, respectively. Cell density under $\mathrm{f} / 2(\mathrm{~N}-)$ increased slightly on day 16 reaching an average of ca. $43 \times 10^{6}$ cells $\mathrm{mL}^{-1}$, whereas it remained stable with ca. $35 \times 10^{6}$ cells $\mathrm{mL}^{-1}$ under $\mathrm{f} / 2$ (P-) (Fig. 1a). Biomass production reached its highest values under nutrient deprivation (Fig. 1b) and was significantly higher under f/2 (N-) (ca. $980.0 \pm 100.0 \mathrm{mg} \mathrm{L}^{-1}$ ) than under f/2 (P-) (ca. $800.0 \pm$ $\left.40 \mathrm{mg} \mathrm{L}^{-1}\right)(p<0.05)$ (Fig. 1b). Biomass productivity under 



Fig. 1 Growth, biomass production and nutrient kinetics of $N$. oceanica CCALA 978 under complete $\mathrm{f} / 2$ and nutrient deprivation conditions. a Growth curves; $\mathbf{b}$ biomass production (DCW: dry cell weight); $\mathbf{c}$ biomass productivity; and $\mathbf{d}$ nitrate and phosphate concentrations. In $\mathbf{a}, \mathbf{b}, \mathbf{d}$, the

$\mathrm{f} / 2\left(\mathrm{~N}-\right.$ ) reached ca. $49 \pm 2.1 \mathrm{mg} \mathrm{L}^{-1}$ day $^{-1}$ (Fig. 1c) and was significantly higher $(p<0.05)$ than under complete $\mathrm{f} / 2$ and $\mathrm{f} / 2$ (P-) $(p<0.05)$, without significant differences between complete $\mathrm{f} / 2$ and $\mathrm{f} / 2(-\mathrm{P})(p>0.05)$. The growth rate of $N$. oceanica CCALA 978 with complete $\mathrm{f} / 2$ was within the same range as that for other species growing in complete medium, such as $N$. salina $\left(0.49 \mathrm{day}^{-1},[11]\right)$ and Nannochloropsis sp. $\left(0.33\right.$ day $\left.^{-1}[10]\right)$, but was lower than for the $N$. oceanica CCALA $804\left(0.83 \mathrm{day}^{-1}\right)$ and Nannochloropsis sp. $\left(0.76\right.$ day $\left.^{-1}\right)$ strains studied by Pal et al. [13] and Griffiths et al. [12], respectively. The differences among the values reported could be due to variations in the environmental conditions employed (such as continuous light, photoperiod, light intensities). When the species studied in the present work was deprived of nitrate or phosphate, there was a marked increase in biomass production, particularly under nitrogen deficiency, indicating a metabolite accumulation stage.

Nutrient kinetics under complete $\mathrm{f} / 2$ medium and under both nitrate and phosphate deprivation were also analysed (Fig. 1d). Under complete $\mathrm{f} / 2$, phosphate presented a consumption rate of $14.5 \mu \mathrm{M} \mathrm{day}^{-1}$ in 2 days and that of nitrate $117 \mu \mathrm{M}$ day $^{-1}$ in 4 days, leading to a ca. 30 -fold and ca. 15 fold decrease in nitrate and phosphate content, respectively. It is noteworthy how the luxury uptake of both macronutrients in

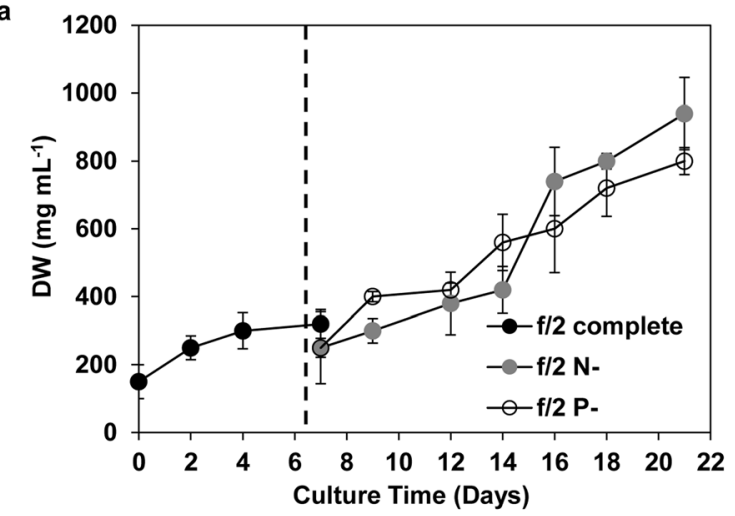

b

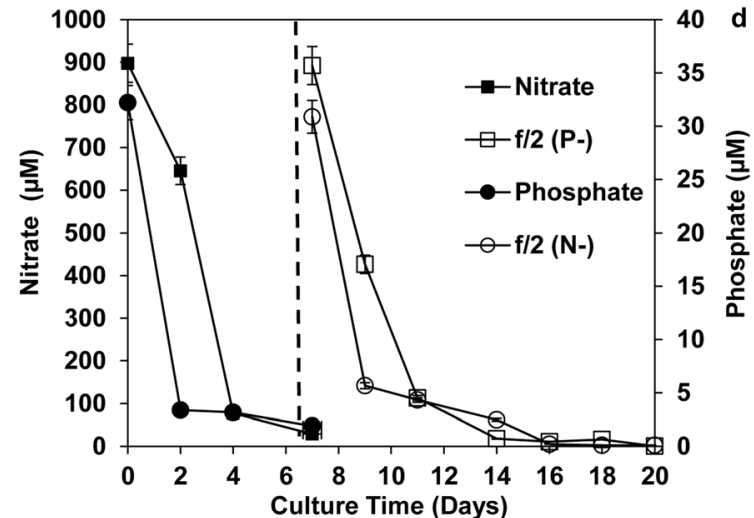

dashed line indicates the beginning of the nitrate or phosphate deprivation phase. Data are expressed as the average \pm standard deviation of three replicates. CD, cell density; DCW, dry cell weight; f/2 (N-), nitrate deprivation; $\mathrm{f} / 2(\mathrm{P}-)$, phosphate deprivation

the first days of culture step 1 contributed to cell growth and consequently to increased cell density (Fig. 1a). Under nutrient deprivation conditions (culture step 2), the consumption rates of nitrate and phosphate $\left(155.9 \mu \mathrm{M} \mathrm{day}^{-1}\right.$ and $5.3 \mu \mathrm{M} \mathrm{day}^{-1}$, respectively, over 5 days) were significantly lower than under complete $\mathrm{f} / 2(p<0.05)$, resulting in a ca. 8 fold and ca.7-fold decrease in the initial levels, respectively. These trends indicate that the absence of a nutrient $(\mathrm{N}$ or $\mathrm{P})$ affects the absorption of available nutrients ( $\mathrm{N}$ or $\mathrm{P})$, causing a decrease in cell growth.

With respect to the pigment kinetics of $N$. oceanica CCALA 978, chlorophyll- $a$ content increased up to ca. $900 \times 10^{-3} \mu \mathrm{g} \mathrm{mL}^{-1}$ on day 4 (culture step 1), while under nutrient deprivation, it dropped to $400 \times 10^{-3} \mu \mathrm{g} \mathrm{mL}^{-1}$ and $200 \times 10^{-3} \mu \mathrm{g} \mathrm{mL}{ }^{-1}$ in $\mathrm{f} / 2(\mathrm{~N}-)$ and $\mathrm{f} / 2(\mathrm{P}-)$, respectively (Fig. 2a). Carotenoid content increased 5-fold and 1.6-fold under $\mathrm{f} / 2(\mathrm{~N}-)$ and $\mathrm{f} / 2(\mathrm{P}-)$ conditions, respectively, compared with complete $\mathrm{f} / 2$ (Fig. 2b), with an increase in carotenoid content of up to ca. $1100 \times 10^{-3} \pm 15 \mu \mathrm{g} \mathrm{mL} \mathrm{m}^{-1}$ under nitrate deprivation (Fig. 2b). The UV-Vis pigment absorption spectra of $N$. oceanica under control and nitrate deprivation conditions are shown in Fig. 2c. Under control conditions, the spectrum exhibited (1) two peaks typical for Chl $a$, one at $430 \mathrm{~nm}$ and one at $663 \mathrm{~nm}$; and (2) a peak at $473 \mathrm{~nm}$, which represent 

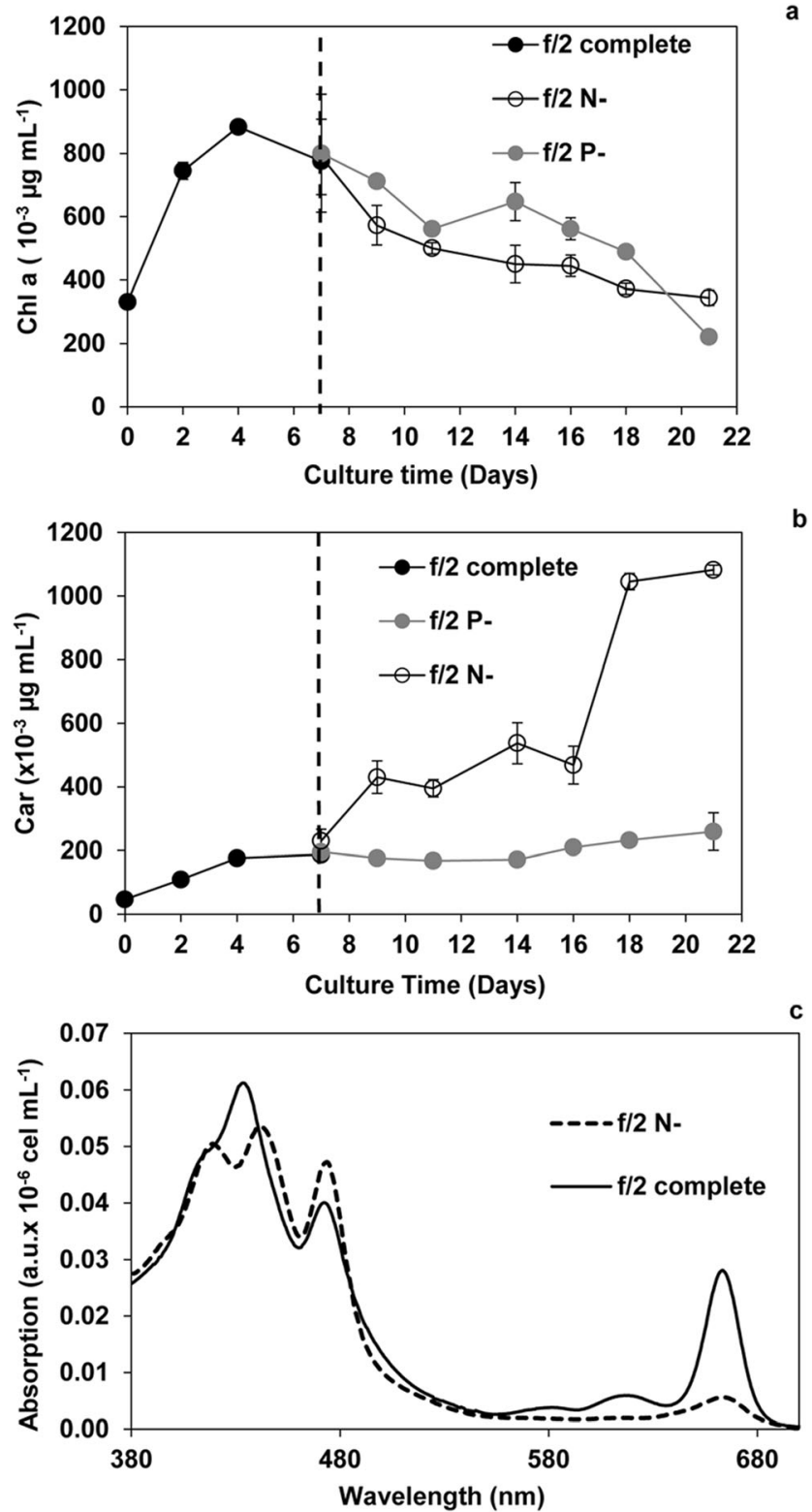

Fig. 2 Pigment kinetics of $N$. oceanica CCALA 978. a Chlorophyll- $a$ (Chl a) concentration kinetics; b carotenoid concentration kinetics (Car) and $\mathbf{c}$ absorption spectrum of pigments under nitrate deprivation and control conditions. In $\mathbf{a}, \mathbf{b}$, the dashed line indicates the beginning of the nitrate or phosphate deprivation phase. Data are expressed as the average \pm standard deviation of three replicates. $\mathrm{f} / 2(\mathrm{~N}-)$, nitrate deprivation; $\mathrm{f} / 2$ (P-), phosphate deprivation. Spectra were normalized to the cellular density

the sum of contribution from some carotenoids. Under nitrate deprivation, the signals between 400 and $500 \mathrm{~nm}$ were more diverse, with a higher contribution in the absorption at $473 \mathrm{~nm}$, while the Chl $a$ peak at 663 decreased with respect to control conditions. Thus, the $\mathrm{Chl} a /$ Car ratios (663/473) were 0.70 and 0.12 under control and nitrate deprivation conditions, respectively, suggesting an increase in carotenoids when $\mathrm{N}$ is lacking. Primary photosynthetic carotenoids are associated with thylakoid membranes and are synthesized under favourable growth conditions, whereas secondary carotenoids are not involved in photosynthesis and are produced under stress culture conditions (for example, nitrogen starvation, high light intensities and high salinity) [39]. The lack of $\mathrm{N}$ in the studied strain could thus be related to the production of secondary carotenoids. The genus Nannochloropsis is a source of valuable carotenoids, such as violaxanthin (Vio), $\beta$-carotene, zeaxanthin (Zea), antheraxanthin, vaucheriaxanthin (Vau) and its fatty acid esters (VE) [7, 14]. In particular, increased Zea content in $N$. oceanica IMET1 under nitrogen deprivation and increased VE content in $N$. oceanica CCALA 804 under both nitrogen starvation and high light intensity have been reported by Dong et al. [23] and Solovchenko et al. [14], respectively. In contrast, Vio and $\beta$ carotene content decreased under $\mathrm{N}$-free medium [14]. Zeaxanthin has been associated with photoprotection and thermal dissipation of absorbed light in N. oceanica IMET1 [23]. Furthermore, among several tested species, Nannochloropsis granulata showed the highest antioxidant properties under the stationary phase with limiting nutrients [40]. Even though no pigment composition was reported in the present study, the high carotenoid levels in the studied strain suggest its potential as a source of antioxidant compounds. For Nannochloropsis sp., Ma et al. [41] reported increased carotenoid production at low light intensity $\left(50 \mu \mathrm{mol} \mathrm{m} \mathrm{m}^{-2} \mathrm{~s}^{-1}\right)$. In fact, this is an advantage for outdoor mass cultivation where the light intensity can be attenuated inside the pond with increasing cell densities. On the other hand, there was no significant increase in carotenoids under $\mathrm{f} / 2$ (P-) condition in the strain studied. It is important to note that the effect of phosphate deficiency on pigment behaviour in $N$. oceanica has not been reported in the literature yet. Therefore, all new information is relevant to establish which nutrient is the most effective for triggering and enhancing carotenogenesis in the studied strain.

\section{Neutral Lipid Accumulation Kinetics}

The neutral lipid (NL) kinetics of $N$. oceanica expressed as the relative fluorescence intensity of neutral lipids (RFI-NL) under both complete $\mathrm{f} / 2$ and nutrient deprivation are shown in Fig. $3 \mathrm{a}$ and b. The RFI-NL increased 3 -fold from day 2 to day 7 (until ca. $800 \mathrm{au}$ ) under complete $\mathrm{f} / 2$, coinciding with a sharp decrease in nutrient concentrations and an increase in cell density (Fig. 1d). Under nutrient deprivation conditions (Fig. 3b), RFI-NL values increased significantly, indicating an accumulation of neutral lipids. Under $\mathrm{f} / 2(\mathrm{~N}-)$, the RFINL values (RFI-NL $>6500 \mathrm{au}$ ) showed an 8-fold increase in 7 days (from day 7 to day 14 of culture), whereas the RFI-NL values under $\mathrm{f} / 2$ (P-) increased 8 -fold in 11 days (from day 7 to day 18). Thus, the main difference between the results of the two nutrient deprivation conditions was in the length of the period of neutral lipid accumulation. The significant increase in biomass observed in N. oceanica CCALA 978 under 

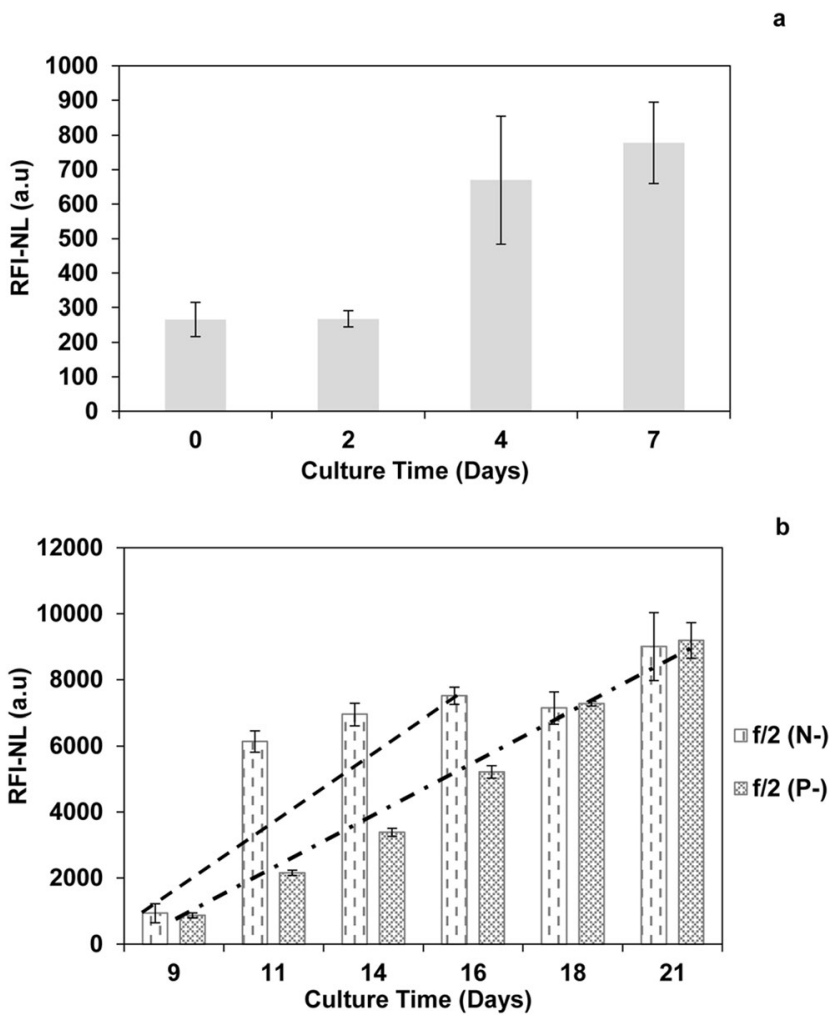

Fig. 3 Neutral lipid accumulation kinetics of N. oceanica CCALA 978. a Complete medium condition; $\mathbf{b}$ nutrient deprivation conditions. In $\mathbf{b}$, lines indicate the accumulation time of NL under the two nutrient deprivation conditions (dashed line: $\mathrm{f} / 2(\mathrm{~N}-)$; dash-dotted line: $\mathrm{f} / 2(\mathrm{P}-)$ ). Data are expressed as the average \pm standard deviation of three replicates

nutrient deprivation (Fig. 1b) can be partially explained by neutral lipid accumulation. Moreover, the RFI-NL kinetics were positively correlated with the biomass kinetics under nutrient deprivation $(r=0.82$ and $r=0.96$ for $\mathrm{f} / 2(\mathrm{~N}-)$ and $\mathrm{f} /$ 2 (P-), respectively, $p<0.05)$. The carotenoid kinetics also showed an important increase when $\mathrm{N}$ was lacking. Thus, nitrate deprivation is a good stress strategy for producing neutral lipids for biodiesel and value-added pigments in N. oceanica CCALA 978 under a biorefinery approach.

\section{Lipid Content}

Figure 4 a shows the content of total lipids (TL) and lipid fractions (neutral lipids (NL), glycolipids (GL) and phospholipids (PL)) of $N$. oceanica CCALA 978 as a percentages of dry weight $(\% \mathrm{dw})$. Under complete $\mathrm{f} / 2$ medium, the TL were ca. $12 \% \mathrm{dw}$, whereas they increased significantly $(p<0.05)$ under nutrient deprivation conditions due to accumulation of neutral lipids. In particular, TL reached their maximum level (ca. 39\% dw) under $\mathrm{f} / 2(\mathrm{~N}-$ ), the neutral lipid content being ca. $35.7 \% \mathrm{dw}$ (Fig. 4a). In terms of lipid fractions, TL were composed of ca. $52 \% \mathrm{NL}$ and ca. $48 \%$ polar lipids under complete $\mathrm{f} / 2$, whereas under $\mathrm{f} / 2(\mathrm{~N}-)$, NL represented ca. $92 \%$ of TL (Fig. 4b). These results are in agreement with those obtained

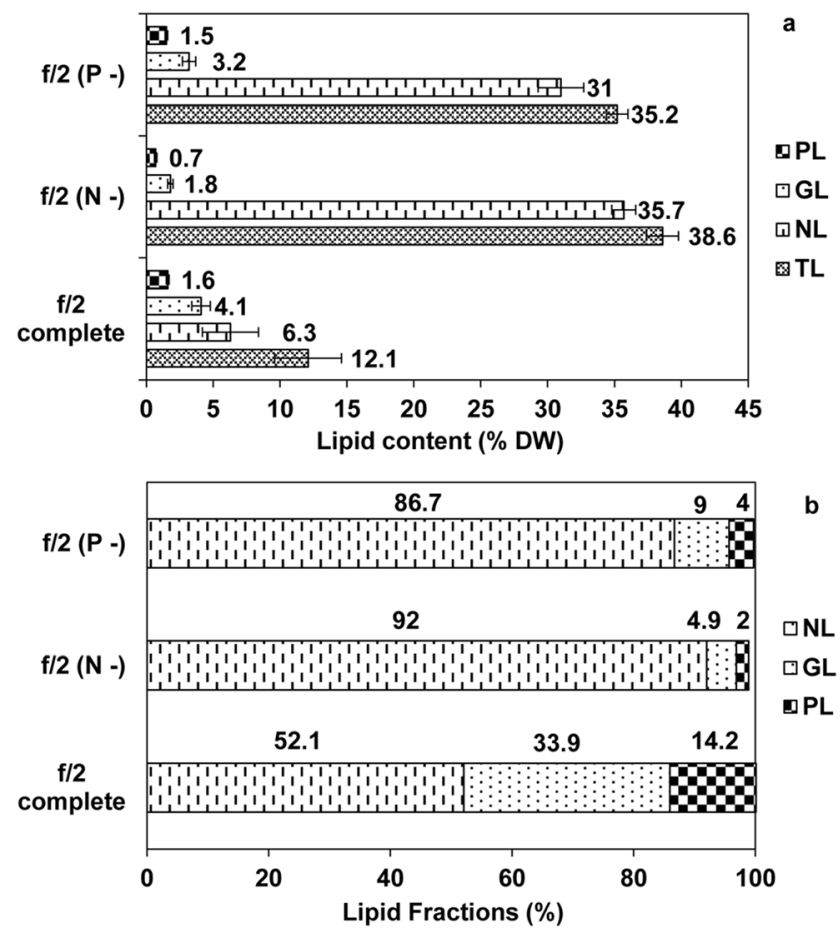

Fig. 4 Lipid content of $N$. oceanica CCALA 978 under control and Nand $\mathrm{P}$ - conditions. a Total lipid and lipid fraction content (expressed as a percentage of dry weight, $\% \mathrm{dw}$ ); $\mathbf{b}$ relative proportion of lipid fractions (expressed as \% of total lipids). Data are expressed as average \pm standard deviation of three replicates. $\mathrm{f} / 2(\mathrm{~N}-)$, nitrogen deprivation; $\mathrm{f} / 2$ (P-), phosphorous deprivation; TL, total lipids; NL, neutral lipids; GL, glycolipids; PL, phospholipids

with other Nannochloropsis species, where neutral lipids, TAG in particular, increased under nitrate deprivation [16, $42,43]$. This behaviour ensures an adequate stock of lipids suitable for biodiesel production by transesterification [44]. Both glycolipid and phospholipid contents decreased significantly under $\mathrm{f} / 2(\mathrm{~N}-)$, representing the lowest values $(1.8 \% \mathrm{dw}$ (GL) and $0.7 \% \mathrm{dw}(\mathrm{PL})$ ); there were no significant differences $(p>0.05)$ between $\mathrm{f} / 2(\mathrm{P}-)$ and complete $\mathrm{f} / 2$ media (Fig. $4 \mathrm{a})$. According to Zezza et al. [45], the phosphorus found in biodiesel comes from the phospholipids contained in the oil used as feedstock. High phosphorus levels have been shown to damage the catalytic converters used in emission control systems and the low phosphorus content in the oil of the studied strain under nitrate deprivation therefore assures good biodiesel quality. Moreover, a maximum level of $10 \mathrm{mg} \mathrm{kg}^{-1}$ of phosphorus in biodiesel samples has been established by the ASTM 6751 standard.

The lipid content of the studied species is similar to those found in other Nannochloropsis oceanica strains. For example, Iwai et al. [46] reported similar TAG content in $N$. oceanica (Nannochloropsis sp. NIES-2145) under phosphorus and nitrogen deprivation. Dong et al. [23] indicated values of ca. $37 \% \mathrm{dw}$ of TL on day 16 of culture and a maximum of ca. $59 \% \mathrm{dw}$ of TL on day 31 under natural nitrogen depletion $\left(20^{\circ} \mathrm{C}\right.$ under 14:10 dark:light photoperiod, 
$100 \mu \mathrm{mol}$ photons $\mathrm{m}^{-2} \mathrm{~s}^{-1}$ and continuous $\mathrm{CO}_{2}$ bubbling). Based on our results, it is important to highlight that the increase in biomass production observed in $N$. oceanica CCALA 978 under phosphorus and nitrogen deprivation was due in part to neutral lipid accumulation rather than an increase in cell density. In addition, the accumulation of neutral lipids was accompanied by an increase in the carotenoid production when the strain grew under nitrogen deprivation. On the other hand, the lack of $P$ would not exert the same effect on carotenogenesis in the studied strain.

\section{Lipid Classes and Fatty Acid Profiles}

Table 1 shows the main fatty acids (saturated (SFA), monounsaturated (MUFA) and polyunsaturated fatty acids (PUFA)) corresponding to total lipids (TL), neutral lipids (NL), glycolipids (GL) and phospholipids (PL) in $N$. oceanica CCALA 978 under complete f/2 medium and nutrient deprivation conditions. The fatty acid profiles showed strong variations among these conditions. As is to be expected given that LN makes up ca. 52\% of TL (the rest being polar lipids), the total lipid profile under complete $\mathrm{f} / 2$ reflected an equal contribution of each lipid fraction. In the TL profile, the dominance of SFA followed by MUFA was therefore a reflection of the neutral lipid profile, while PUFA (ca. 26\%) were the largest component of polar lipids. The dominance of PUFA in PL was due to the high percentage of eicosapentaenoic acid (C20:5n3) (EPA) (ca. $41 \%$ in PUFA-GL and ca. $28 \%$ in PUFA-PL). $N$. oceanica also produced arachidonic (ARA), linoleic (LA) and linolenic (ALA) acids, particularly in phospholipids. This composition is common during the active growth phase in Nannochloropsis species, as occurred during the culture step 1 with complete $\mathrm{f} / 2$, where the cells presented high percentages of PUFA (for example, EPA and DHA).

Under nutrient deprivation, TL profiles mainly revealed the contribution of neutral lipids (NL $>80 \%$ of TL, Fig. 4b). Under $\mathrm{f} / 2(\mathrm{~N}-)$, MUFA were the dominant class due to the high percentage of C16:1 (ca. 37\%), followed by SFA with a high percentage of C16:0 (ca. $34 \%)$. A significant decrease $(p<0.05)$ in EPA was detected in $\mathrm{NL}$ under $\mathrm{f} / 2(\mathrm{~N}-)$. Under $\mathrm{f} / 2(\mathrm{P}-)$, the SFA class was dominant due to the high concentration of $\mathrm{C} 16: 0$ (ca. $44 \%$ ), followed by MUFA with a high concentration of C16:1 (ca. 28\%). Thus, our results indicate three important features of $N$. oceanica CCALA 978 as follows: (1) PUFA derived mainly from the polar fraction under optimal growth conditions; (2) f/2 (N-) produced a significant increase in MUFA $(p<0.05)$ for both TL (ca. 55\%) and NL (ca.54\%) fractions due to the dominance of $\mathrm{C} 16: 1$ and the minimum PUFA value and (3) f/2 (P-) produced a significant increase $(p<0.05)$ in SFA due to the dominance of C16:0. Fatty acid profiles obtained in this work are in agreement with those reported in the literature for other strains of $N$. oceanica growing under different conditions [14, 23, 47, 48]. However, the neutral lipid fatty acid profile of the studied strain under $\mathrm{f} / 2(\mathrm{~N}-)$ presented the best balance among the lipid classes necessary for high-quality biodiesel production (MUFA $(54.1 \%)>$ SFA $(40.24 \%)>$ PUFA $(5.96 \%)$ ).

\section{Biodiesel Quality from Fatty Acid Profiles}

High-quality biodiesel production requires, among other factors, the use of oils with high neutral lipid content and with a suitable fatty acid profile [49]. Fatty acids with a carbon chain length ranging from $\mathrm{C} 16$ to $\mathrm{C} 18$, such as palmitic (C16:0), palmitoleic (C16:1), stearic (C18:0) and oleic (C18:1) acids, ensure adequate biodiesel properties as they provide a reasonable balance between cetane number, cold flow, oxidative stability and combustion properties [50]. Since the maximum level of neutral lipids was obtained with $\mathrm{f} / 2(\mathrm{~N}-)$, the biodiesel quality was inferred from the total lipid and neutral fraction profiles under nitrate deprivation (Table 2). The estimated parameters were compared with those cited for several strains of $N$. oceanica by Ma et al. [44] and with the US and European Standards.

The iodine value, cetane number, kinematic viscosity and specific gravity of the biodiesel produced from the studied species meet the standards established by EN 14214 and U.S. (ASTMD 6751-08) and are similar to those estimated for other $N$. oceanica strains [44]. Cloud point and cold filter plugging point were also estimated for $N$. oceanica oils, though there are no specifications relating to these properties owing to seasonal differences between geographical regions. The cloud point of the studied strain was higher $\left(8.6^{\circ} \mathrm{C}\right.$ and $9.9^{\circ} \mathrm{C}$ in TL and NL, respectively) than those reported by Ma et al. [44] for the $N$. oceanica IMET1 and N. oceanica 805 strains; but it was lower than the one indicated in $N$. oceanica CCMP531. Poor cloud points arise in the presence of longchain saturated fatty acids [36]. According to $N$. oceanica CCALA 978 profiles, the amount of palmitic acid in the neutral lipids was relatively high, which would contribute to a poor cloud point. However, the cold filter plugging point (CFPP), which measures the temperature at which fuel can no longer pass through a filter in a given time [51], was adequate for temperatures below $0{ }^{\circ} \mathrm{C}$.

From an environmental viewpoint, one of the most attractive characteristics of biodiesel is its high biodegradability; however, this characteristic makes it susceptible to oxidative and thermal degradation. Some of the factors affecting oxidative stability during storage and commercialization are PUFA presence [50], light, high temperatures, humidity, enzymes, metallic elements and pigments [52]. With respect to PUFA 


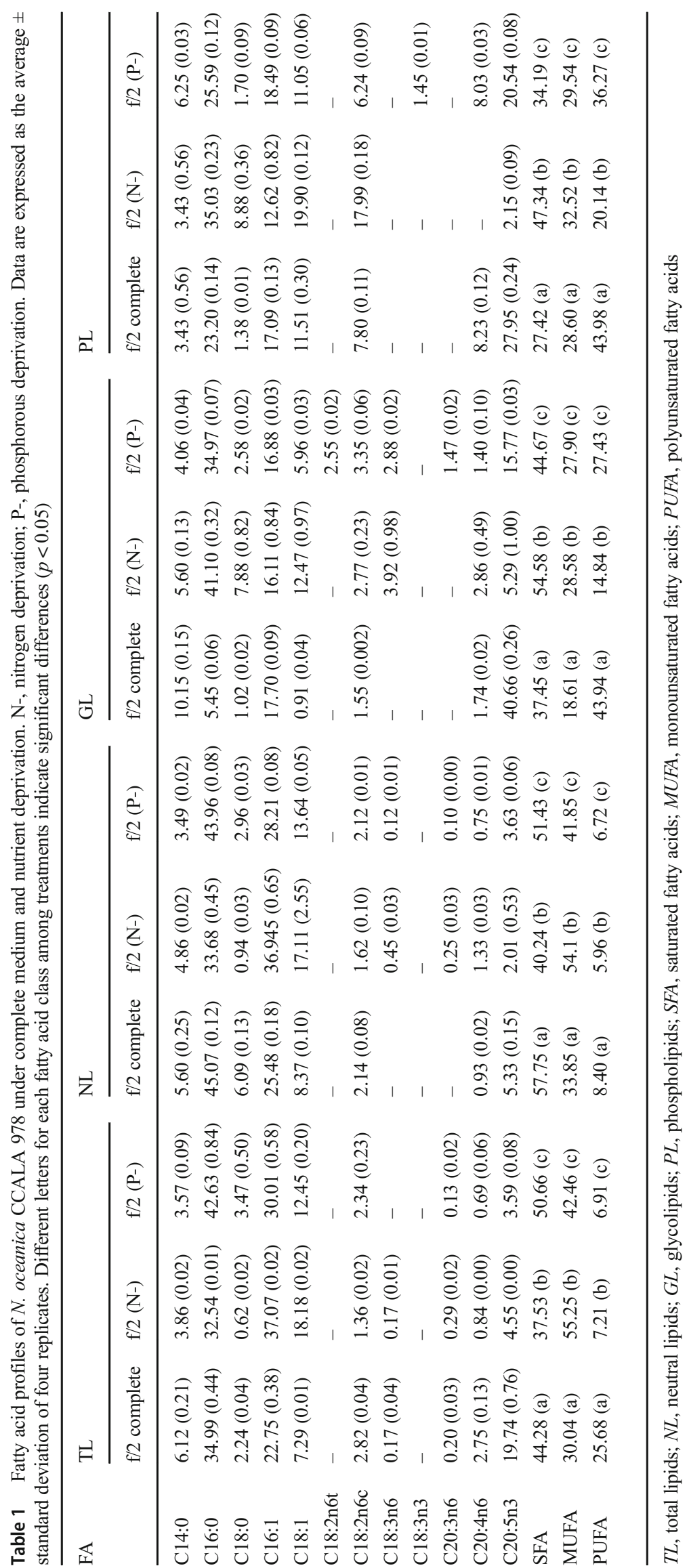




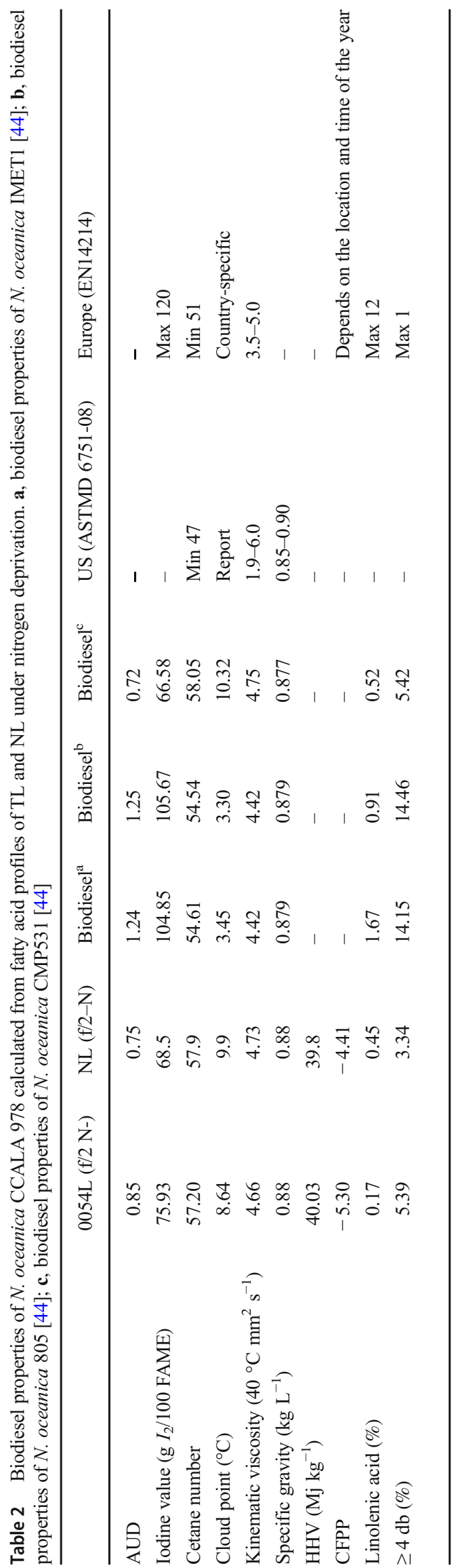

content, the European EN Standard 14214 requires a maximum of $12 \%$ linolenic acid methyl ester and a maximum of $1 \%$ fatty acid methyl ester with four or more double bonds (CEN 2003) [53]. These specifications are necessary to prevent the oxidation of the double bonds and thus ensure an adequate oxidative stability of the biodiesel. The linolenic acid content of $N$. oceanica CCALA 978 was very low $(0.12$ $0.45 \%$ ); even though PUFA with more than 4 double bonds exceeded the standard, the EPA content in the studied species under $\mathrm{f} / 2(\mathrm{~N}-)$ was the lowest in comparison with other values in $N$. oceanica strains [23, 47]. Synthetic antioxidants have been used to prevent oxidation of biodiesel and other fuels (e.g., butylated hydroxyanisole, butylated hydroxytoluene, propyl gallate and tertiary butylhydroquinone) [54]. Unfortunately, most of these antioxidants exhibit poor biodegradability and they are usually expensive. On the other hand, tocopherols, ascorbic acid, flavonoids and carotenoids are readily biodegradable, non-toxic natural antioxidants, able to improve the oxidative stability of fuels [52]. Thus, the high carotenoid levels in the studied strain suggest its potential as a source of antioxidant compounds. Moreover, lipids and carotenoids may simultaneously be extracted by using supercritical carbon dioxide as has been reported for other microalgae [55]. This extraction technique is particularly suitable when thermo-labile compounds are present since it is easy to separate them from the extract and to avoid the use of toxic solvents $[3,56]$.

\section{Conclusions}

Nannochloropsis oceanica CCALA 978 cultures under nutritional stress conditions ( $\mathrm{N}$-free or P-free media) showed a significant increase of neutral lipid content. However, the neutral lipid accumulation period was shorter under nitrate deprivation. Moreover, the carotenoid kinetics also showed an important increase when $\mathrm{N}$ was lacking. Therefore, a biorefinery approach encourages testing the production of neutral lipids with natural antioxidants from cultures of $N$. oceanica CCALA 978 in order to obtain biodiesel and blends with reduced oxidative vulnerability. In addition, under these conditions, the oils produced would ensure biodiesel with low phosphorus content, as well as CN, KV and SG meeting the quality conditions established by EN 14214 and US 404 (ASTMD 6751-08) standards.

Funding information Funds were provided by the Consejo Nacional de Investigaciones Científicas y Técnicas (CONICET) de la República Argentina (PIP 112-2015 01-00510), the Agencia Nacional de Promoción Científica y Tecnológica (BID PICT 2015-0800) and the Universidad Nacional del Sur (PGI 24/B246). CAP is a Research Member of the Comisión de Investigaciones Científicas de la Provincia de Buenos Aires (CIC) and PIL is a Research Member of CONICET. 


\section{References}

1. Liu J, Song Y, Qiu W (2017) Oleaginous microalgae Nannochloropsis as a new model for biofuel production: review and analysis. Renew Sust Energ Rev 72:154-162. https://doi.org/ 10.1016/j.rser.2016.12.120

2. Hu Q, Sommerfeld M, Jarvis E, Ghirardi M, Posewitz M, Seibert M, Darzins A (2008) Microalgal triacylglycerols as feedstocks for biofuel production: perspectives and advances. Plant J 54:621-639. https://doi.org/10.1111/j.1365-313X.2008.03492.x

3. Hegel P, Martín L, Popovich CA, Damiani MC, Pancaldi S, Pereda S, Leonardi PI (2017) Biodiesel production from Neochloris oleoabundans by supercritical technology. Chem Eng Process Process Intensif 121:232-239. https://doi.org/10.1016/j.cep.2017. 08.018

4. Popovich CA, Pistonesi M, Hegel P, Constenla D, Barnech Bielsa G, Martín L, Damiani MC, Leonardi PI (2019) Unconventional alternative biofuels: quality assessment of biodiesel and its blends from marine diatom Navicula cincta. Algal Res 39:101438. https:// doi.org/10.1016/j.algal.2019.101438

5. Zhu B, Sun F, Yang M, Lu L, Yang G, Pan K (2014) Large-scale biodiesel production using flue gas from coal-fired power plants with Nannochloropsis microalgal biomass in open raceway ponds. Bioresour Technol 174:53-59. https://doi.org/10.1016/j.biortech. 2014.09.116

6. Moreno Garcia L, Adjallé K, Barnabé S, Raghavan GSV (2017) Microalgal biomass production for biorefinery system: recent advances and the way towards sustainability. Renew Sust Energ Rev 76:493-506. https://doi.org/10.1016/j.rser.2017.03.024

7. Nobre BP, Villalobos F, Barragan BE, Oliveira AC, Batista AP, Marques PASS, Mendez RL, Sovová H, Palavra AF, Gouveia L (2013) A biorefinery from Nannochloropsis sp. microalgaextraction of oils and pigments. Production of biohydrogen from the leftover biomass. Bioresour Technol 135:128-136. https://doi. org/10.1016/j.biortech.2012.11.084

8. Bielsa GB, Popovich CA, Rodríguez MC, Martínez AM, Martín LA, Matulewicz MC, Leonardi PI (2016) Simultaneous production assessment of triacylglycerols for biodiesel and exopolysaccharides as valuable co-products in Navicula cincta. Algal Res 15:120-128. https://doi.org/10.1016/j.algal.2016.01.013

9. Molina Grima E, Belarbi EH, Acien Fernández FG, Medina Robles A, Chisti Y (2003) Recovery of microalgal biomass and metabolites: process options and economics. Biotechnol Adv 20:491-515. https://doi.org/10.1016/S0734-9750(02)00050-2

10. Huerlimann R, De Nys R, Heimann K (2010) Growth, lipid content, productivity, and fatty acid composition of tropical microalgae for scale-up production. Biotechnol Bioeng 107:245-257. https:// doi.org/10.1002/bit.22809

11. Sforza E, Bertucco A, Morosinotto T, Giacometti GM (2012) Photobioreactors for microalgal growth and oil production with Nannochloropsis salina: from lab-scale experiments to large-scale design. Chem Eng Res Des 90:1151-1158. https://doi.org/10.1016/ j.cherd.2011.12.002

12. Griffiths MJ, van Hille RP, Harrison STL (2012) Lipid productivity, settling potential and fatty acid profile of 11 microalgal species grown under nitrogen replete and limited conditions. J Appl Phycol 24:989-1001. https://doi.org/10.1007/s10811-011-9723-y

13. Pal D, Khozin-Goldberd I, Cohen Z, Boussiba S (2011) The effect of light, salinity and nitrogen availability on lipid production by Nannochloropsis sp. Appl Microbiol Biotechnol 90:1429-1441. https://doi.org/10.1007/s00253-011-3170-

14. Solovchenko A, Lukyanov A, Solovchenko O, Didi-Cohen S, Boussiba S, Khozin-Goldberg I (2014) Interactive effects of salinity, high light, and nitrogen starvation on fatty acid and carotenoid profiles in Nannochloropsis oceanica CCALA 804. Eur J Lipid Sci Technol 116:635-644. https://doi.org/10.1002/ejlt.201300456

15. Mitra M, Patidar SK, Mishra S (2015) Integrated process of two stage cultivation of Nannochloropsis sp. for nutraceutically valuable eicosapentaenoic acid along with biodiesel. Bioresour Technol 193:363-369. https://doi.org/10.1016/j.biortech.2015.06.033

16. Bondioli P, Della Bella L, Rivolta G, Chini Zittelli G, Bassi N, Rodolfi L, Casini D, Prussi M, Chiaramonti D, Tredici MR (2012) Oil production by the marine microalgae Nannochloropsis sp. F\&M-M24 and Tetraselmis suecica F\&M-M33. Bioresour Technol 114:567-672. https://doi.org/10.1016/j.biortech.2012.02. 123

17. Xiao Y, Zhang J, Cui J, Yao X, Sun Z, Feng Y, Cui Q (2015) Simultaneous accumulation of neutral lipids and biomass in Nannochloropsis oceanica IMET1 under high light intensity and nitrogen replete conditions. Algal Res 11:55-62. https://doi.org/10. 1016/j.biortech.2012.02.123

18. Meng Y, Cao X, Yao C, Xue S, Yang Q (2017) Identification of the role of polar glycerolipids in lipid metabolism and their acyl attribution for TAG accumulation in Nannochloropsis oceanica. Algal Res 24:122-129. https://doi.org/10.1016/j.algal.2017.03.004

19. Chua ET, Schenk PM (2017) A biorefinery for Nannochloropsis: induction, harvesting, and extraction of EPA-rich oil and high-value protein. Bioresour Technol 244:1416-1424. https://doi.org/10. 1016/j.biortech.2017.05.124

20. Leu S, Boussiba S (2014) Advances in the production of high-value products by microalgae. Ind Biotechnol 10:169-183. https://doi. org/10.1089/ind.2013.0039

21. Mitra M, Patidar SK, George B, Shah F, Mishra S (2015b) A euryhaline Nannochloropsis gaditana with potential for nutraceutical (EPA) and biodiesel production. Algal Res 8:161-167. https://doi. org/10.1016/j.algal.2015.02.006

22. Sathasivam R, Ki JS (2018) A review of the biological activities of microalgal carotenoids and their potential use in healthcare and cosmetic industries. Mar Drugs 16:26-57. https://doi.org/10.3390/ md16010026

23. Dong HP, Williams E, Wang DZ, Xie ZX, Hsia RC, Jenck A, Halden R, Li J, Chen F, Place AR (2013) Responses of Nannochloropsis oceanica IMET1 to long-term nitrogen starvation and recovery. Plant Physiol 162:1110-1126. https://doi.org/10. 1104/pp.113.214320

24. Bongiovani N, Sánchez Puerta MV, Popovich C, Leonardi P (2014) Molecular and phylogenetic identification of an oil-producing strain of Nannochloropsis oceanica (Eustigmatophyceae) isolated from the southwestern Atlantic coast (Argentina). Rev Biol Mar Oceanogr 49:615-623. https://doi.org/10.4067/S071819572014000300019

25. Guillard RRL (1973) Division rates. In: Stein JR (ed) Handbook of phycological methods: culture methods and growth measurements. Cambridge University Press, Cambridge, pp 289-311

26. Chini Zittelli G, Pastorelli R, Tredici MR (2000) A modular flat panel photobioreactor (MFPP) for indoor mass cultivation of Nannochloropsis sp. under artificial illumination. J Appl Phycol 12:521-526. https://doi.org/10.1023/A:1008165606234

27. Bongiovani N, Popovich C, Martinez AM, Freije H, Constenla D, Leonardi P (2013) In vivo measurements to estimate culture status and neutral lipid accumulation in Nannochloropsis oculata CCALA 978: implications for biodiesel oil studies. Algol Stud 142:3-16. https://doi.org/10.1127/1864-1318/2013/0104

28. Talling JF, Driver D (1963) Some problems in the estimation of chlorophyll a in phytoplankton. Proceedings of the Conference of Primary Productivity Measurement, Marine and Freshwater, University of Hawaii, Honolulu, Atomic Energy Commission TID-7633, pp 142-146.

29. Strickland JDH, Parsons TR (1968) A practical handbook of seawater analysis. Bull Fish Res Bd Canada 167:311 
30. Murphy J, Riley IP (1962) A modified single solution method for the determination of phosphate in natural waters. Anal Chim Acta 27:31-36

31. Strickland JDH, Parsons TR (1972) A practical handbook of sea water analysis, 2nd edn. Bull. Fich. Res. Bd, Canadá 268 pp

32. Folch J, Lees M, Sloane Stanley GH (1957) A simple method for the isolation and purification of total lipids from animal tissues. $\mathrm{J}$ Biol Chem 226:497-509

33. Converti A, Casazza AA, Ortiz EY, Perego P, Del Borgui M (2009) Effect of temperature and nitrogen concentration on the growth and lipid content of Nannochloropsis oculata and Chorella vulgaris for biodiesel production. Chem Eng Process 48:1146-1151. https://doi. org/10.1016/j.cep.2009.03.006

34. Berge JP, Gouygou JP, Dubacq JP, Durand P (1995) Reassessment of lipid composition of the diatom Skeletonema costatum. Phytochem 39:1017-1021. https://doi.org/10.1016/0031-9422(94) 00156-N

35. Morrison WR, Smith LM (1964) Preparation of fatty acid methyl esters and dimethylacetals from lipids with boron fluoride-methanol. J Lipid Res 5:600-608

36. Hoekman SK, Broch A, Robbins C, Ceniceros E, Natarajan M (2012) Review of biodiesel composition, properties, and specifications. Renew Sust Energ Rev 16:143-169. https://doi.org/10.1016/ j.rser.2011.07.143

37. Talebi AF, Mohtashami SK, Tabatabaei M, Tohidfar M, Bagheri A, Zeinalabedini M, Mirzae HH, Mirzajanzadeh M, Shafaroudi S, Bakhtiari S (2013) Fatty acids profiling: a selective criterion for screening microalgae strains for biodiesel production. Algal Res 2:258-267. https://doi.org/10.1016/j.algal.2013.04.003

38. Di Rienzo JA, Casanoves F, Balzarini MG, Gonzalez L, Tablada M, Robledo CW (2008) InfoStat, versión 2008. Grupo InfoStat, FCA, Universidad Nacional de Córdoba, Argentina

39. Solovchenko AE (2013) Physiology and adaptive significance of secondary carotenogenesis in green microalgae. Russ J Plant Physiol 60:1-13. https://doi.org/10.1134/S1021443713010081

40. Banskota AH, Sperker S, Stefanova R, McGinn PJ, O’Leary SJB (2019) Antioxidant properties and lipid composition of selected microalgae. J Appl Phycol 31:309-318. https://doi.org/10.1007/ s10811-018-1523-1

41. Ma R, Thomas-Hall SR, Chua ET, Eltanahy E, Netzel ME, Netzel G, Lu Y, Schenk PRM (2018) LED power efficiency of biomass, fatty acid, and carotenoid production in Nannochloropsis microalgae. Bioresour Technol 252:118-126. https://doi.org/10. 1016/j.biortech.2017.12.096

42. Suen Y, Hubbard JS, Holzer G, Tornabene TG (1987) Total lipid production of the green alga Nannochloropsis sp. QII under different nitrogen regimes. J Phycol 23:289-296. https://doi.org/10.1111/ j.1529-8817.1987.tb04137.x

43. Rodolfi L, Chini Zittelli G, Bassi N, Padovani G, Biondi N, Bonini G, Tredici MR (2009) Microalgae for oil: strain selection, induction of lipid synthesis and outdoor mass cultivation in a low-cost photobioreactor. Biotechnol Bioeng 102:100-112. https://doi.org/ 10.1002/bit.22033

44. Ma Y, Wang Z, Yu C, Yin Y, Zhou G (2014) Evaluation of the potential of 9 Nannochloropsis strains for biodiesel production.
Bioresour Technol 167:503-509. https://doi.org/10.1016/j. biortech.2014.06.047

45. Zezza TCR, de Souza CM, Ramos Stradio N (2012) Determination of phosphorus in biodiesel using 1:12 phosphomolybdic modified electrode by cyclic voltammetry. Fuel 95:15-18. https://doi.org/10. 1016/j.fuel.2011.12.035

46. Iwai M, Hori K, Sasaki-Sekimoto Y, Shimojima M, Ohta H (2015) Manipulation of oil synthesis in Nannochloropsis strain NIES-2145 with a phosphorus starvation-inducible promoter from Chlamydomonas reinhardtii. Front Microbiol 6:912-927. https:// doi.org/10.1016/j.fuel.2011.12.035

47. Xiao Y, Zhang J, Cui J, Feng Y, Cui Q (2013) Metabolic profiles of Nannochloropsis oceanica IMET1 under nitrogen-deficiency stress. Bioresour Technol 130:731-738. https://doi.org/10.1016/j. biortech.2012.11.116

48. Murakami H, Nobusawa T, Hori K, Shimojima M, Otha H (2018) Betaine lipid is crucial for adapting to low temperature and phosphate 9 deficiency in Nannochloropsis. Plant Physiol 177:181-193. https://doi.org/10.1104/pp.17.01573

49. Knothe G (2008) "Designer" biodiesel: optimizing fatty ester composition to improve fuel properties. Energy Fuel 22:1358-1364. https://doi.org/10.1021/ef700639e

50. Knothe G (2005) Dependence of biodiesel fuel properties on the structure of fatty acid alkyl esters. Fuel Process Technol 86:10591107. https://doi.org/10.1016/j.fuproc.2004.11.002

51. Stansell GR, Gray VC, Sym SD (2012) Microalgal fatty acid composition: implications for biodiesel quality. J Appl Phycol 24:791801. https://doi.org/10.1007/s10811-011-9696-x

52. de Sousa LS, Rodarte de Moura V, de Oliveira JE, Miranda de Moura E (2014) Use of natural antioxidants in soybean biodiesel. Fuel 134:420-428. https://doi.org/10.1016/j.fuel.2014.06.007

53. European Committee for Standardization (CEN) EN-14214: 2003 (2003) Automotive fuels. Fatty acid methyl esters (FAME) for diesel engines. Requirements and test methods. http://www.cen.eu

54. Rawat DS, Joshi G, Pandey JK, Lamba BY, Kumar P (2018) Algal biodiesel stabilization with lower concentration of 1: 3 ratios of binary antioxidants-key factors to achieve the best synergy for maximum stabilization. Fuel 214:471-479. https://doi.org/10. 1016/j.fuel.2017.11.056

55. Goto M, Kanda H, Wahyodiono MS (2015) Extraction of carotenoids and lipids from algae by supercritical $\mathrm{CO}_{2}$ and subcritical dimethyl ether. J Supercrit Fluids 96:245-251. https://doi.org/10. 1016/j.supflu.2014.10.003

56. Sánchez-Camargo AP, Martinez-Correa HA, Paviani LC, Cabral FA (2011) Supercritical $\mathrm{CO}_{2}$ extraction of lipids and astaxanthin from Brazilian red spotted shrimp waste (Farfantepenaeus paulensis). J Supercrit Fluids 56:164-173. https://oi.org/10.1016/ j.supflu.2010.12.009

Publisher's Note Springer Nature remains neutral with regard to jurisdictional claims in published maps and institutional affiliations. 